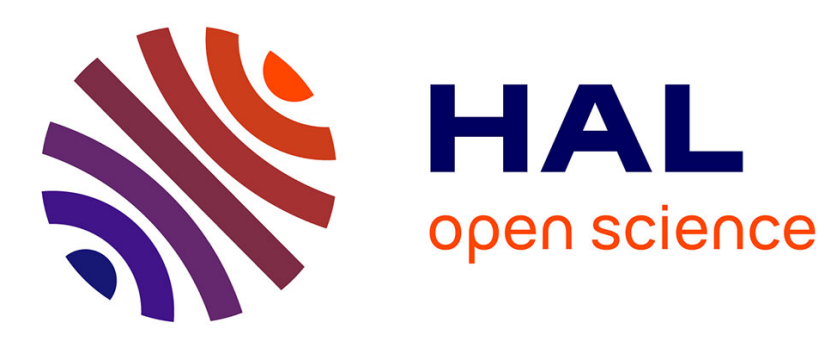

\title{
Key Issues in Local Job Accessibility Measurement: Different Models Mean Different Results
}

\author{
M. Bunel, E. Tovar
}

\section{To cite this version:}

M. Bunel, E. Tovar. Key Issues in Local Job Accessibility Measurement: Different Models Mean Different Results. Urban Studies, 2014, 51 (6), pp.1322-1338. 10.1177/0042098013495573 . halshs00867924

\section{HAL Id: halshs-00867924 \\ https://shs.hal.science/halshs-00867924}

Submitted on 1 Oct 2013

HAL is a multi-disciplinary open access archive for the deposit and dissemination of scientific research documents, whether they are published or not. The documents may come from teaching and research institutions in France or abroad, or from public or private research centers.
L'archive ouverte pluridisciplinaire HAL, est destinée au dépôt et à la diffusion de documents scientifiques de niveau recherche, publiés ou non, émanant des établissements d'enseignement et de recherche français ou étrangers, des laboratoires publics ou privés. 


\title{
Key Issues in Local Job Accessibility Measurement: Different Models Mean Different Results
}

\author{
Bunel Mathieu and Tovar Elisabeth
}

March 2013

\begin{abstract}
This methodological paper shows that using different local job accessibility models (LJA) lead to significantly different empirical appreciations of job accessibility. Matching several exhaustive micro data sources on the Paris region municipalities, we benchmark a representative set of LJA measurement models used in recent literature and an original model where i) we fully estimate job availability according to a set of individual characteristics, ii) we fully model job competition on the local labour market and iii) we control for frontier effects. We show that the model-induced empirical differences are spatially differentiated across the Paris region municipalities, and that failing to fully estimate job availability may lead to over-estimate the job accessibility levels of under-privileged municipalities.
\end{abstract}

Keywords: job competition, local job accessibility, methodological issues, microdata, Paris, spatial econometrics

JEL classification: C18, J64, R23.

\section{Introduction}

Since John Kain's formulation of the Spatial Mismatch (SM) hypothesis (Kain, 1968), it is widely acknowledged that accessibility is a key factor when understanding individual differences in unemployment and job search success rates. In the Spatial Mismatch Hypothesis, several mechanisms come to play (residential segregation, employment decentralisation and spatial frictions in job search and commuting) to explain poor outcomes in the labour and land markets: unemployment, low earnings and/or low house price rents... For instance, in Kain's seminal work, the African American low employment rate was due to the increasing distance between their inner-city residential location and the jobs that were being progressively relocated in the suburbs, poor accessibility to jobs leading to high unemployment.

Many papers have tested both the empirical reality of Kain's hypothesis and the relative importance of its determinants: individual characteristics, job access, employment decentralisation and residential segregation. On the US context, early empirical studies presented mixed conclusions. Kain (1992) and Ilhanfledt and Sjoquist (1998) pointed that these discrepancies probably stemmed from 
methodological difficulties when assessing local job accessibility (LJA). Subsequent papers, using improved LJA measures, did validate the SM Hypothesis, showing that poor LJA does have an adverse effect on employment outcomes (Ong and Miller, 2005; Johnson, 2006).

On the European context, empirical studies of the SM are fewest and more recent, but growing evidence indicates that European cities (and Paris in particular)are increasingly vulnerable to SM either because of increasingly socially differentiated urban sprawl (Cheshire, 1995) or of residential location-driven discrimination on the labour market (Duguet et al., 2012)... Among this burgeoning European Spatial Mismatch empirical literature, see Houston (2005) and Patacchini and Zenou (2005) for British cities; for Dutch cities, see Musterd et al.(2003) and van der Klaauw and van Ours (2003); on Brussels, see Dujardin et al. (2008); on Madrid and Barcelona, see Matas et al. (2009). On the Paris context, the results are quite contradictory on both the reality of the SM and on the relative role of its determinants. Whereas Gaschet and Gaussier (2004), Gobillon and Selod (2007) and Duguet et al. (2009) find a weak or inexistent negative effect of poor LJA on employment, Korsu and Wenglenski (2010) find that low job accessibility significantly affects long-term unemployment for under-skilled workers.

Interestingly, many of these papers rely on different LJA measures: one can therefore wonder whether the discrepancies found in this literature reflect actual empirical differences or do simply stem from the model used to assess LJA. Following Morris et al. (1979), Handy and Niemeier (1997) and Ilhanfledt and Sjoquist (1998), we aim to provide empirical evidence on this matter. Our question is not to provide new insights on the SM hypothesis by disentangling the relative effects of job accessibility and local and individual characteristics on joblessness. We focus on the methodological question of assessing if and how different strategies of local job accessibility (LJA) measurement may result in different findings. If empirical differences are methodologically-induced, the collective effort in the construction of improved LJA measures - to which we contribute in this paper by proposing an original LJA model -should be carried on. Also, it is interesting to assess which aspects of the LJA measurement lead to notable empirical differences and should therefore be carefully modelled, and which have little empirical impact. Such a methodological endeavour may be important form a publicpolicy point of view, especially if the methodologically-induced empirical differences are spatially differentiated across the city's territory. If so, the LJA model choice may significantly affect the recommendations on the local targeting of anti-Spatial Mismatch public policies.

In Section 2, we present the key methodological issues of LJA measurement (proximity, frontier effects, job availability and job competition modelling) and propose an original alternative model that uses national exhaustive micro data. In Section 3, we present our data and study area, the Paris Region. Section 4 develops the benchmarking strategy used to test the hypothesis that using different LJA models leads to significantly different assessments of LJA levels. In Section 5, we show that this hypothesis is empirically validated, identify the model dimensions that induce significant empirical 
discrepancies and show that the model-induced differences are spatially differentiated across the Paris Region municipalities. In Section 6 we conclude and briefly discuss desirable strategies for developing further LJA measures.

\section{Measuring LJA: Literature Review and Original Extension}

There are at least five key methodological issues when measuring LJA. First, one must deal with job proximity, i.e. model how geographical distance affects the ability to seek and hold jobs and address the issue of frontier effects. A second factor to consider is mobility, with the modelling of unequal access to transportation, as well as congestion and local differences in density and frequency in the public transportation networks. Third, one must take into account job availability (Ihlanfeldt and Sjoquist, 1998), i.e. the possibility of a qualitative match between the skill requirements of the job offers and the individual skills of the job seekers. Fourth, LJA measurement must encompass local job competition. To do so, the best strategy is to $i$ ) use a direct measure of vacancies instead of all the existing jobs (Ihlanfeldt and Sjoquist, 1998) and ii) only count as competitors the jobless workers and employed workers who are actually seeking a new job, instead of all the workers. Lastly, because of the increasing flexibility of the labor market, the possibility to commute between home and several jobs should be modeled.

In this paper, we do not tackle all of these issues. Dealing with too many methodological dimensions would create a great number of possible combinations, which would complicate the empirical benchmarking presented in the paper. Also, from a practical point of view, taking into account all five aspects of LJA measurement would mean matching a great number of geo-referenced databases which were not available to us at a micro level. We therefore do not model the unequal access to automobile transportation and base our estimations on car time-distance commutes only, discarding public transportation issues (contrary to Détang-Dessandre and Gaigné, 2009, and Matas et al., 2009). Also, because of data availability issues, we use occupied jobs and active workers instead of vacancies and actual job seekers, as in Jayet (2000) and Korsu and Wenglenski (2010) ${ }^{1}$.We focus on the following three key aspects of the LJA measurement literature: (1) job reachability, (2) job availability and (3) job competition and propose an original model that allows for a full estimation these elements.

\footnotetext{
${ }^{1}$ The use ofsuch suboptimal variables is less critically problematic for benchmarking purposes, as in this paper, than if our aim was to provide the most accurate picture of Spatial Mismatch. There are no guarantees that filled and vacant jobs (or active and unemployed workers) are identically dispersed across a city's municipalities. In particular, the potential spatial disjunction of the spatial clustering of unemployed workers and of vacant jobs has no reason to be the same as between clusters of filled jobs and active workers. Raphael (1998) advocates for local job growth as an alternative variable, but there is no guarantee either that job growth is correlated with the actual number of available jobs in any census tract, or that such a correlation would be identical across all municipalities.
} 


\subsection{Modelling how distance affects job reachability}

Assessing job reachability means tackling two different issues. First, it means modelling job proximity, i.e. delimiting the area within which jobs can be reached by any given worker so that jobs that distant from the worker's residential location are less reachable that closer ones. Second, frontier effects must be addressed.

\section{Job Proximity}

In the literature, different models $p_{k}$ are used to measure the proximity of any job located in municipality $t^{\prime}$ with any worker living in municipality $t$ ( $c f$. Box 1 for the mathematical presentation of all specifications discussed below).At an extreme, distance can be thought as being insuperable: a city's municipalities are modelled as isolated local labour markets and the pool of jobs considered to be within a worker's reach is equal to the ones that are located in his residential municipality. In the Paris region, by contrast, $71.70 \%$ of the employed males did not work on their residential municipality in 2006. At the other extreme, if spatial frictions are null, there is only one regional-sized global labour market and all jobs are reachable to any worker, irrelevantly of his residential location.

Between these polar and trivial cases, three models coexist in the literature. In the discrete approach (model $\mathrm{p}_{1}$ ), all jobs within a particular distance are reachable, while those that are located further are excluded from the worker's local labour market. For example, Korsu and Wenglenski (2010) consider that jobs that are located less than 60 minutes away from one's residential municipality are reachable, such as in Equation (1).

In continuous models with decay function (Bania et al., 2008, Allard and Danziger, 2002, Cervero et al., 1999, Sanchez et al., 2004), jobs are given weights that are inversely correlated with distance. Proximity between municipalities $t$ and $t^{\prime}$ can be either measured using straight-line distance (Equation 2 , model $\mathrm{p}_{2}$ ) or time travel (Equation 3 , model $\left.\mathrm{p}_{3}\right)^{2}$.

Finally, as in Rogers (1997), a mixed model $\left(\mathrm{p}_{4}\right)$ uses concentric time-travel rings within which all jobs receive the same weight, as in Equation (4), where decay coefficients of models $\mathrm{p}_{2}, \mathrm{p}_{3}$ and $\mathrm{p}_{4}$ were obtained using a gravity model (Equation 5). The mixed model allows a better fitting with actual transportation patterns than using a decay function. Moreover, using an exponential decay function as in Equations (2) and (3) over-weigh distant jobs and under-weight closer ones ${ }^{3}$. In our original model, we assess proximity using this mixed method.

\footnotetext{
${ }^{2}$ Note that Hansen (1959) also proposes to use the inverse power function.

${ }^{3} \mathrm{~A}$ job located 15 minutes away from a worker's residential location is given a weight ranging between 0.85 and 0.75 while a job located 1 hour away from a worker's residential location is given a weight ranging between 0.55 and 0.33 .
} 


\section{Box 1. Benchmark specifications for measuring job proximity}

Discrete time-distance model (model $\mathrm{p}_{1}$ )

$$
\text { Pool }_{t}^{p_{1}}=\sum_{t^{\prime}} I\left(\text { Time }_{t t^{\prime}} \leq 60^{\prime}\right) J o b_{t^{\prime}}
$$

Continuous straight-line distance model (model $\left.\mathrm{p}_{2}\right)$

$$
\operatorname{Pool}_{t}^{p_{2}}=\sum_{t^{\prime}} J_{o b} b_{t^{\prime}} e^{\left(-\lambda \text { Dist }_{t t^{\prime}}\right)}
$$

Continuous time travel distance model (model $\left.\mathrm{p}_{3}\right)$

$$
\text { Pool }_{t}^{p_{3}}=\sum_{t^{\prime}} J_{o b} b_{t^{\prime}} e^{\left(-\lambda \text { Time }_{t t^{\prime}}\right)}
$$

Discrete concentric rings

$$
\begin{gathered}
\text { Pool }_{t}^{p_{4}}=\sum_{t^{\prime}} I\left(\text { Time }_{t t^{\prime}} \leq 5^{\prime}\right) J o b_{t}+\exp \left(\gamma_{1}\right) \sum_{t^{\prime}} I\left(5^{\prime}<\text { Time }_{t t^{\prime}} \leq 15^{\prime}\right) J o b_{t}+ \\
\exp \left(\gamma_{2}\right) \sum_{t^{\prime}} I\left(15^{\prime}<\text { Time }_{t t^{\prime}} \leq 20^{\prime}\right) J o b_{t}+\exp \left(\gamma_{3}\right) \sum_{t^{\prime}} I\left(20^{\prime}<\text { Time }_{t t^{\prime}} \leq 30^{\prime}\right) J o b_{t}+ \\
\exp \left(\gamma_{4}\right) \sum_{t^{\prime}} I\left(30^{\prime}<\text { Time }_{t t^{\prime}} \leq 40^{\prime}\right) J o b_{t}+\exp \left(\gamma_{5}\right) \sum_{t^{\prime}} I\left(40^{\prime}<\text { Time }_{t t^{\prime}} \leq 50^{\prime}\right) J o b_{t}+ \\
\exp \left(\gamma_{6}\right) \sum_{t^{\prime}} I\left(50^{\prime}<\text { Time }_{t t^{\prime}} \leq 60^{\prime}\right) J o b_{t}+\exp \left(\gamma_{7}\right) \sum_{t^{\prime}} I\left(60^{\prime}<\text { Time }_{t t^{\prime}} \leq 80^{\prime}\right) J o b_{t}+ \\
\exp \left(\gamma_{8}\right) \sum_{t^{\prime}} I\left(80^{\prime}<\text { Time }_{t t^{\prime}} \leq 90^{\prime}\right) J_{t}
\end{gathered}
$$

With

Pool $_{t}^{p \bullet}$ the pool of municipality t's potentially reachable jobs under model p•

Dist $_{t t^{\prime}}$ the straight-line distance between municipalities $t$ and $t^{\prime}$.

Time $_{t t^{\prime}}$ the time travel distance between municipalities $\mathrm{t}$ and $\mathrm{t}$ '.

$J o b_{t^{\prime}} \quad$ the number of jobs in municipality $\mathrm{t}^{\prime}$.

$\lambda$ a decay parameter which calibrates the extent to which each additional $\mathrm{km}$ or minute adversely affects job seeking.

$I\left(\right.$ Time $\left._{t t^{\prime}} \leq \tau^{\prime}\right) \quad$ an indicator function equal to 1 if the time travel between municipalities $t$ and $t^{\prime}$ is 


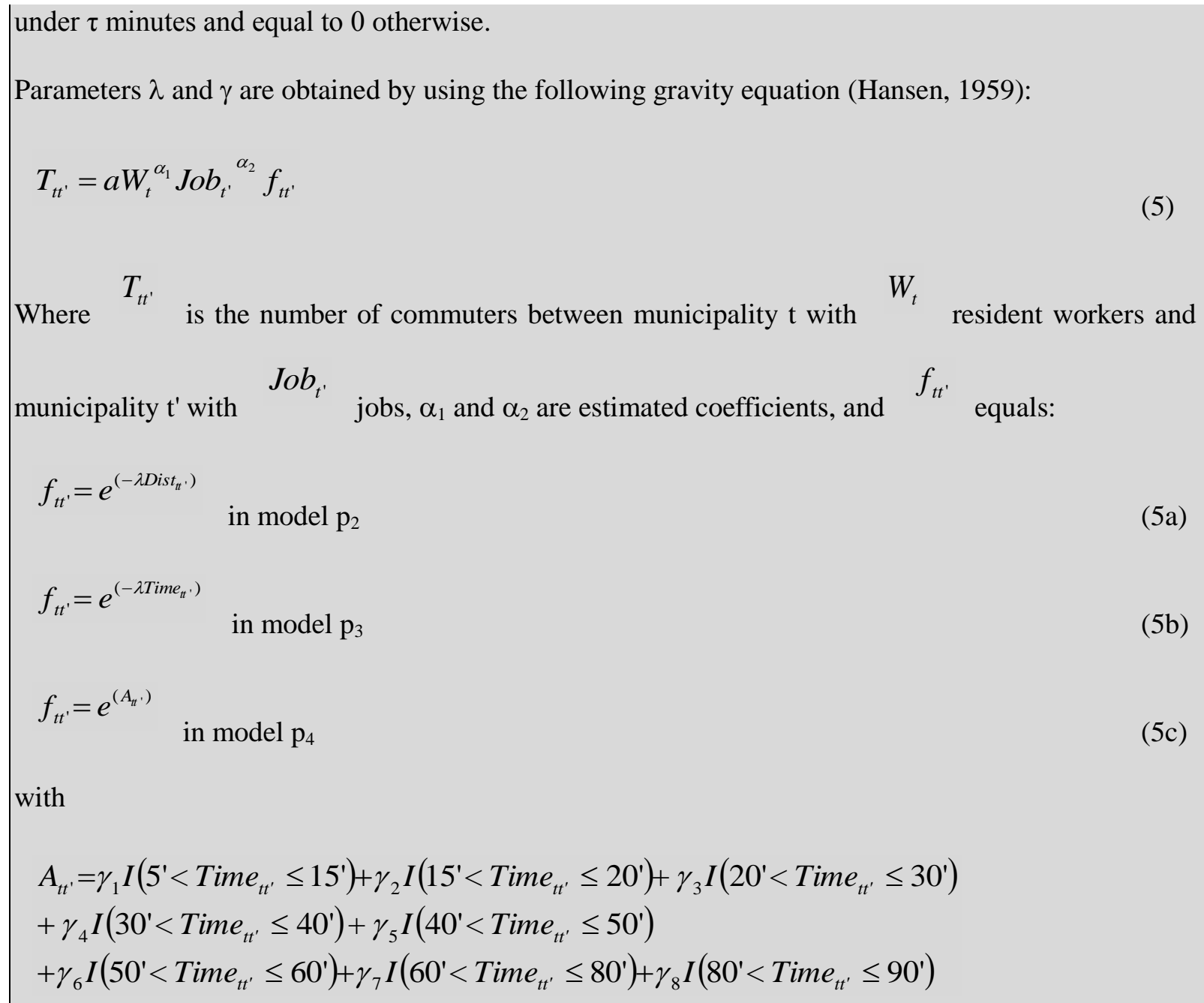

with

$$
\begin{aligned}
& A_{t t^{\prime}}=\gamma_{1} I\left(5^{\prime}<\text { Time }_{t t^{\prime}} \leq 15^{\prime}\right)+\gamma_{2} I\left(15^{\prime}<\text { Time }_{t t^{\prime}} \leq 20^{\prime}\right)+\gamma_{3} I\left(20^{\prime}<\text { Time }_{t t^{\prime}} \leq 30^{\prime}\right) \\
& +\gamma_{4} I\left(30^{\prime}<\text { Time }_{t t^{\prime}} \leq 40^{\prime}\right)+\gamma_{5} I\left(40^{\prime}<\text { Time }_{t t^{\prime}} \leq 50^{\prime}\right) \\
& +\gamma_{6} I\left(50^{\prime}<\text { Time }_{t t^{\prime}} \leq 60^{\prime}\right)+\gamma_{7} I\left(60^{\prime}<\text { Time }_{t t^{\prime}} \leq 80^{\prime}\right)+\gamma_{8} I\left(80^{\prime}<\text { Time }_{t t^{\prime}} \leq 90^{\prime}\right)
\end{aligned}
$$

As in Raphael (1998) we estimate those gravity equations by using negative binomial count regression.

\section{Frontier Effects ${ }^{4}$}

Frontier effects result from the artificial truncation of the pool of reachable jobs within administrative boundaries(model $f_{1}$ ) and are problematic, since workers can and do apply to jobs outside of their residential region and workers face the competition not only of the workers who live in their own residential region, but also of those that live outside its boundaries. For the Paris Region, Figure 1 shows that few of its residents work outside of it. By contrast, the proportion of workers who live outside the region and who work in it is high.In this paper, we use nation-wide datasets and can therefore show whether nullifying frontier effects (model $f_{2}$ ) or not (model $f_{1}$ ) leads to significant empirical discrepancies when measuring LJA.

\footnotetext{
${ }^{4}$ In this paper, we call "frontier effects" the empirical consequences of using geographically truncated data. We do not refer to the literature on the effects of the frontiers themselves on individual or firm behaviour.
} 


\section{Figure 1 here}

\subsection{Job Availability}

Second, even if a job is reachable, it will not necessarily be available to any worker, since individual characteristics determine the actual matching of jobs and workers.

A first model $\left(a_{1}\right)$ consists in using aggregated data both on the supply and the demand side of the market, and comparing the stock of workers living in any given municipality with the stock of jobs that are reachable by them. In this case, the job availability of any municipality is equal to the pool of jobs that are reachable form track $t$ (according to the proximity measure $p_{k}$ ) (Ong and Miller, 2005; Johnson, 2006; Gobillon and Selod, 2007; Bania et al., 2008; Duguet et al., 2009).

Other recent papers use census micro data that allow for a one-dimensional subsetting of the local labour market: in model $\left(\mathrm{a}_{2}\right)$, the job availability for municipality $t$ is equal to the pool of jobs within the subset $q$ that are reachable form track $t$ according to the proximity measure $p_{k}$. This is problematic because it means making implicit assumption that any job of a given socio-economic status (Korsu and Wenglenski, 2010) or education level (Matas et al., 2009) is potentially identically available to any worker of the same socio-economic status (or education level), whereas the relevance of the socioeconomic statuses' definition in French statistics is an ongoing debate (see Héran, 1984; Duriez et al., 1991 for early discussions). The influence of socio-economic affiliation on the decision to apply for any given job and its role on a firm's hiring decisions are dubious. If the probability that a worker with no degree is hired as an executive is likely to be very low, diploma downgrading(déclassement scolaire) is a long-established stylized fact of the French labour market (Fourgeot and Gautié, 1997; Nauze-Fichet and Tomanisi, 2002), and may have worsened in recent years (Chauvel, 2006, DuruBellat, 2006, Maurin, 2009).

In this paper, we propose to use an original job availability measure $\left(a_{3}\right)$ where we estimate a municipality's employment rate by matching its workers and the reachable jobs though a whole set of individual characteristics (see Box 2).

\section{Box 2. Our model}

Step 1.Estimating employment probabilities conditional to individual characteristics

First, using the Labour Force Survey for the 2004-2006 period, we estimate, at the region level and for the active males ${ }^{5}$, the global employment probability of holding a job conditional to the vector of

\footnotetext{
${ }^{5}$ Because of data availability issues, we did not include the female workers in our population. Further work based
} 
individual characteristics $X_{\mathrm{i}}$.

We use different covariates to take into account the individual impact of human capital and tenure on employment probability ${ }^{6}$ : age (four categories: under 25, between 25 and 39, between 39 and 55, over 55), education level (six categories: no qualification, vocational qualifications (BEP, CAP), technical or professional baccalaureate, general baccalaureate, under-graduate and graduate).We also introduce variables on the family status (man living alone, man living in a couple without children under 6, man living in a couple with at least a child under 6) that may influence job search process. We add three additional variables: 1) a covariate representing the homeownership situation ${ }^{7}$ (4 categories: house owner, flat owner; renter of a subsidized home; renter of an unsubsidized home), 2) the unemployment rate of Employment Area (Zone d'Emploi) ${ }^{8}$ to take into account local specificities concerning job opportunities and 3) the worker's employment status the year before since an individual's employment situation depends strongly of his past employment status.

Let $E^{*}$ be latent variable related to the observed employment status (E),

$$
E_{i}^{*}=X_{i} \beta+\eta_{i}
$$

We observe $\mathrm{E}=1$ if the individual $i$ is employed and $\mathrm{E}=0$ otherwise. $X$ are the exogenous explanatory variables presented below and $\beta$ is the vector of coefficients to estimate.

Therefore:

$$
E_{i}= \begin{cases}1 & \text { if } E_{i}^{*}>0 \\ 0 & \text { otherwise }\end{cases}
$$

By assuming that $\eta$ are i.i.d. of a type-I distribution, a simple Logit model follows:

$$
P(E=1 \mid X)-\frac{\exp (\beta X)}{1+\exp (\beta X)}
$$

The marginal effect of this model is obtained by:

on other national databases may be able to bypass this limitation. On a more theoretical level, modeling the female workers' labour market means taking into unequal access to automobile transportation and commuting between several part-time jobs (in Île-de-France, only $10 \%$ of the male workers hold a part-time job, versus $21 \%$ of the female workers).

${ }^{6}$ The list of control variables used in the paper was limited by the availability of geo-located data; further work on other urban areas may profitably use richer geo-located databases (Labor Force Survey, for example) and use a larger list of variables.

${ }^{7}$ Oswald (1996) pointed out the positive correlation between homeownership and unemployment, due to the fact that for homeowners, mowing entails larger transaction costs than for renters.

${ }^{8}$ The French National Statistics Institute defined 348 Employment Areas (Zones d'Emploi) determined by the fact that most of the people who live in such area also work in it. 


$$
\frac{\partial P(E=1 \mid X)}{\partial X}-\frac{\exp (\beta X)}{[1+\exp (\beta X)]^{2}} \beta
$$

\section{Step 2.Estimating the workers' predicted labour market situation.}

Then, for each active male worker $i$ who lives in any municipality $t=1, \ldots, T=1300$ of the Paris region, we use the Dwellings census database to collect the information on his vector of individual characteristics $\mathrm{X}_{\mathrm{i}}$. Using the global coefficients $\hat{\beta}$ for the individual characteristics estimated in Step 1, we can therefore estimate the global employment probability $\hat{P}_{i t}$ of each active male $i$ living in district $t$ of the Dwellings census database.

To determine the predicted probability of labour market situation for the workers of the French Census we use the accept-reject simulator. The estimates $\hat{P}_{i t}$ allows us to calculate the deterministic part of probability. To determine the predicted choices we assess the stochastic part of the probability of each choice. For that purpose we draw in a type I extreme value (Weibull) distribution some series of pseudo residuals $\quad \hat{P}_{i t} \quad$ for $i=1, \ldots, N$ and $t=1, \ldots, T$.

The c.d.f. of a Weibull distribution is $F(\eta)=\exp (-\exp (-\eta))$. Then a drawn $x$ in a random distribution (Halton serie) gives a pseudo-residual $\quad \hat{\eta}_{i t}=-\ln (-\ln (x))$. For each draw we determine which professional situation is obtained. The simulated probability is the proportion of draws that are accepts.

Let's define an indicating variable $I_{t}^{r}$ such as: $\begin{cases}I_{t}^{r}=1 & \text { if } \hat{U}_{i t}^{r}>0 \\ I_{t}^{r}=0 & \text { otherwise }\end{cases}$

So, we first compute $U_{i t}^{r}=\hat{\beta} X_{i}+\hat{\eta}_{i t}$

Then, the simulated probability is calculated as follows: $\hat{P}_{I}(t)=\frac{1}{R} \sum_{r=1}^{R} I_{i t}^{r}$

We fix $R$ at 300 for the calculation of each simulated probability.

Step 3.Estimating the available job pool for each municipality

Using the ASDS database, we compute, for each district $t$, the number of existing jobs. With the 
reachability measures defined in Section 2.1., we then determine the pool of jobs that are reachable to any individual living in the district $t$. Finally, by multiplying the accessible jobs stock with the individual estimated employment probabilities $\hat{\boldsymbol{P}}_{i t}$, we estimate ${ }^{9}$ the pool of jobs $\mathrm{Avail}_{t}$ that are available to any worker $i$ living in municipality $t$.

\subsection{Local Job Competition}

The last issue is the modelling of job competition (model $\mathrm{c}_{\mathrm{m}}$ ). Even if a job is reachable by and available to a worker, its actual accessibility also depends on the number of competitors that could also claim to form a match with it (Weibull, 1976, Ilhanfeldt, 1993, Harris, 2001, Van Wee et al., 2001, Kawabata and Shen, 2007).In most papers on LJA, the competitors of the tract $t$ workers are usually defined as the workers that are reachable from tract $t$ (Bania et al., 2008; Duguet et al., 2009) (Partial Job Competition, model $\mathrm{c}_{1}$ ): in Figure 2 the competitors of Worker 1 for Job A are the workers who live within Worker 1's prospection ring (blue ring): Worker 3 and Worker 4 are both computed as Worker 1's competitors for Job A, while Worker 2 is not. However, in Figure 2 Job A is clearly within Worker 2's and outside Worker 3's prospection rings: Worker 4 and Worker 2 should be included among the competitors of Worker 1 for Job A, while Worker 3 shouldn't (see Détang-Dessandre and Gaigné, 2009, for a similar discussion).

Here, we use a full definition of job competition (model $c_{2}$ ). We identify the reachable and available jobs $j$ for any worker $i$ living in municipality $t$ and measure, for each of these jobs, the number of actual labour market competitors, i.e. the number of workers whom the job is also reachable and available. The number of competitors for worker $i$ is the sum of his actual competitors for all jobs $j$ without double counting. Then, for any municipality $t$, LJA is defined as the ratio of weighted reachable jobs to the number of labour market competitors for these jobs.

\section{Figure 2here}

\footnotetext{
${ }^{9}$ Appendix 1 provides the results at the district (département) level. When comparing our results with the aggregated observed employment situation described in administrative files (ADSD and unemployed database of Pôle Emploi), we observe some small differences, but the magnitude and the rank of the departments are roughly respected.
} 


\section{Data and area study}

\subsection{The data}

We compute the job access of each male worker between 20 and 55 years old who lived in the Paris region in 2006by measuring his estimated probability of finding a job conditionally to his individual characteristics. To do so, we use survey, census and administrative microdata as well as exhaustive municipality-to-municipality commute times. Descriptive statistics are presented in Appendix 2.

The 2006 French Census Dwellings database provides exhaustive information for the all French territory and at the municipality level, on individual nationality, age, gender, diploma, socio-economic group, job quality, and mobility and dwellings characteristics.

The Annual Declarations of Social Data (ADSD) database is collected by the French Institute for Statistics (INSEE) and includes more than 1.8 million firms. It is mandatory for most employers and self-employed in France for pension, benefits and tax purposes. There is a unique record for each employee/establishment/year combination. The ADSD database includes data on wages, qualifications, industry and geographical localization. Employees included in the ADSD database represented (90\%) of the private labour force in the Paris region in $2006^{10}$.

The Labour Force Survey (LFS) is used to measure unemployment in the sense of the International Labour Organization. This representative survey included 74 000persons over 15 years old living in the metropolitan France. It provides data on professions, working hours and casual employment. French Census Dwellings, ADSD and the LSF come from the French Institute for Statistics (INSEE).

Commute times. For all time-based proximity measures, we use a comprehensive matrix of municipality-to-municipality (centroid) commute times ${ }^{11}$ between all French continental municipalities.

\subsection{The area study}

The Paris Region consists in 1300 municipalities (1280 municipalities or communes and 20 downtown arrondissements) and 8 districts (départements). It is the most populated and economically developed region in France with $21.6 \%$ of the French population in 2006 for $28.1 \%$ of its GDP. Its GDP per capita was 43,818 Euros in 2006 (vs. 28,475 for whole country) and GDP/job was 92,736 Euros (vs.

\footnotetext{
${ }^{10}$ Note that the ADSD database does not include private employees from domestic services or off-shore activities. It represents $80 \%$ of all active workers because some public servants are not incorporated.

${ }^{11}$ This data was computed using the GIS software Chronomap@. Unequal access to cars and/or the public transportation network is a key factor of LJA (Détang-Dessandre and Gaigné, 2009, and Matas et al., 2009) but for availability reasons, we rely exclusively on car-based time distance measurements.
} 
71,415 Euros) (data: INSEE). There were 2.315 million male workers in the Paris region labour market, for 3.977 million available jobs in the private sector. In 2006, $72.60 \%$ of the male workers lived in a district (département) where the ratio between jobs and labour force was above 1 . This ratio was very high in Inner Paris (district 75) and in a 'primary ring' composed by districts 92 (Hauts-deSeine), 93 (Seine Saint Denis) and 94 (Val-de-Marne). It decreased steadily in the outer districts of the region. There were also many intra-regional home-to-work commutes: in 2006 , only $28.30 \%$ of the male workers worked and lived in the same municipality.

\section{Benchmarking strategy}

To assess whether the model specification of local accessibility measurement has a significant empirical effects, we compute the Pearson correlation coefficients ${ }^{12}$ between $i$ ) the LJA levels of the 1300 Paris Region municipalities obtained with a representative selection of the models reviewed in Section 2 and $i$ ) the LJA levels measured with an original, fully estimated, benchmark model.

For all models, LJA of municipality $t$ is defined as the ratio of the number of available jobs to the number of male ${ }^{13}$ labour market competitors that are reachable from municipality $t$ (Equation 9).

$$
\text { Accessibility }_{t}\left(c_{m}, a_{l}, p_{k}, f_{j}\right)=\frac{\text { Available } \operatorname{Jobs}_{t}\left(a_{l}, p_{k}, f_{j}\right)}{\text { Available Competitors } t_{t}\left(c_{m}, a_{l}, p_{k}, f_{j}\right)}
$$

In the original benchmark model (Model B), we fully estimate the job availability probability (model

$a_{2}$ ) and fully take into account the job competition on the labour market (model $m_{2}$ ). We also measure job proximity using the mixed concentric-rings model because it allows a better fitting with actual transportation patterns (model $p_{4}$ ).

We estimate Equation (5c) based on its logarithmic transformation, to obtain the $\gamma_{\mathrm{j}}$ values, which are all significant $\left(\gamma_{1}=-0.88 ; \gamma_{2}=-0.79 ; \gamma_{3}=-0.68 ; \gamma_{4}=-0.55 ; \gamma_{5}=-0.43 ; \gamma_{6}=-0.33 ; \gamma_{7}=-0.21 ; \gamma_{8}=-0.11\right)$.

Finally, because we rely on nation-wide data, we nullify frontier effects ${ }^{14}$ (model $f_{1}$ ).

The "naïve" model (Model N) does not take into account jobs that are located outside a worker's own municipality, is sensitive to frontier effects, does not estimates the job availability probability and partially takes job competition into account.

Models $\mathrm{T} \bullet$ and $\mathrm{G} \bullet$ are similar to the benchmark with the exception of their proximity specification,

\footnotetext{
${ }^{12}$ The whole set of Pearson correlation coefficients computed between all methods is available upon request.

${ }^{13}$ We limit our study to the competition between male workers (see footnote 6). However, we have kept both male- and female-occupied jobs in the pool of "available" jobs.

${ }^{14}$ Assuming no international labour inputs.
} 


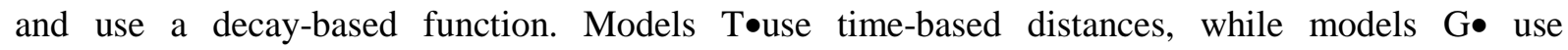
orthodromic distances. Decay parameters $\lambda$ are obtained by estimated equation $5 \mathrm{a}$ and $5 \mathrm{~b}$ (Models T2 and G2). To examine the results sensitivity to the decay parameter $\lambda$, we alternatively set low (Models T1 and G1) and high (Models T3 and G3) values for $\lambda^{15}$. With parameter $\lambda$ set to 0.02 in G• models (0.011 in T• models), jobs located at $10 \mathrm{kms}$ (34 minutes) of a worker's location - which are the average commuting figures in the Capital Region (DREIF, 2011) - have a weight of almost 70\%. Model $\mathrm{F}$ is similar to the benchmark model except that in this model we do not use nation-wide data to measure job proximity, and limit ourselves to jobs that are situated within the Paris Region, therefore riddling the results with frontier effects. In Model C, job competition is not fully measured, by contrast with the benchmark model B. Last but not least, in Model A we do not fully estimate the job availability probability.

\section{Results}

The results presented in Table 1 show that $i$ ) using different models for assessing LJA does lead to significantly different empirical results and that, moreover, ii) the empirical discrepancies particularly affect unprivileged areas.

\section{Table 1 here}

First, as far as proximity is concerned, relying on distance-based models instead of time-based ones is likely to lead to very different results: distance-based Models G• are clearly very poorly correlated with the time-based benchmark mode ${ }^{16} \mathrm{~B}$ (Pearson coefficient equal to 0.447 for the strongest decay parameter). This is especially true for the "frontier municipalities": time-based models should therefore be used whenever possible in order to accurately take into account the effects of transportation system structure on the assessment of LJA.

Also, among time-based models, if using a continuous, decay-based specification (Models T•) versus a concentric-rings one (benchmark Model B) does not lead to significant different results when focusing on all municipalities, once again differences arise for the farthest municipalities. However, for frontier municipalities, where jobs are more distant from the workers, the difference is bigger, even if decay-based specifications (Models T•) tend to overweight distant jobs.

\footnotetext{
${ }^{15}$ Results from the gravity model give $\lambda=0.02$ for G2 model and $\lambda=0.011$ for T2 model. Computations are available upon request. To check on robustness to a wide range of decay parameters we introduce the following parameters: $\lambda=0.01, \lambda=0.02$ and $\lambda=0.03$ for G• models and $\lambda=0.002, \lambda=0.011$ and $\lambda=0.020$ for $\mathrm{T} \bullet$ models. The results are robust.

${ }^{16}$ Note that our findings say nothing a priori about the superiority of the reference model.
} 
Interestingly, among time- and distance-based models, the decay parameter $\lambda$ does not have a significant empirical impact on LJA measurement: whatever the sub-group of municipalities, models T1, T2 and T3's correlation with the benchmark model B are very similar, and the same is true for models G1, G2 and G3. This means that, at least for a roughly monocentric region such as the Paris Region the decay parameter specification is not likely to matter much, since the job gradient with the distance to the central business district is pretty steep anyway. This could be different for more polycentric regions.

Second, poor frontier effects management (in Model F) doesn't affect much the LJA ranking of the Paris region municipalities (correlation coefficient equal to 0.887 with the benchmark model). An explanation may be that all other major French job clusters (Lyon, Marseille, Bordeaux, Strasbourg...) are far from the Paris Region, which is surrounded by a vast area where there are very few jobs. As a result, failing to register the jobs located outside the Paris region frontier is not likely to modify the LJA level of any given municipality. Not surprisingly, this is however less true for the "frontier municipalities", where poor frontier effects management leads to a drop of the correlation coefficient to 0.533 .

Third, fully or partially taking into account the extent of job competition (Model C) does not lead to very different LJA rankings (correlation coefficient equal to 0.765). However, again, this is less true for some specific municipalities: namely, for the "residential municipalities", the LJA levels correlation coefficient drops to a mere 0.673 . These municipalities are predominantly located at the outskirt of the Paris urban area; due to the ongoing suburbanization of the Paris region, they house many suburbanites who massively commute towards Inner Paris, which still concentrates the majority of available jobs. For these workers, using a partial measurement of job competition means ignoring the competition of the many other distant suburbanites who also seek jobs in Inner Paris - but who come from suburbs that are far away from their own prospection ring. Not taking fully into account the job competitors could therefore lead to artificially overestimate the LJA of residential suburbs, preventing the identification (and alleviation) of their specific employment difficulties.

Finally, we find interesting results as far as job availability is concerned. Strikingly, we find no evidence of any significant differences between the LJA ranking of the Paris region municipalities with (Model B) or without (Model A) fully estimating the job availability probability (correlation coefficient equal to 0.971). Moreover, this result holds for all municipality sub-groups, and particularly for deprived and high-unemployment municipalities. For these municipalities, we expected that estimating more accurately the job availability probability would lead to significantly different (and lower) LJA levels; this is not, apparently, the case.

However, the picture shifts when we depart from an aggregated point of view and examine the spatial dispersion of the differences in LJA levels between models A and B. 


\section{Figure 3here}

As visible in Figure 3, the expected difference is real for a cluster of municipalities, where failing to use a full estimation of the job availability probability leads to over-estimate the local job accessibility level (in blue in Figure 3). This cluster spreads, from the Northern municipalities of Inner Paris to Roissy, across most of the Seine-Saint-Denis (93) district. It regroups municipalities that are particularly deprived, whatever the measure of deprivation (Tovar and Bourdeau-Lepage, 2013).As a result, fully estimating LJA does clearly highly matter, from a spatialized point of view, in order to avoid under-estimating the low job accessibility levels of the most underprivileged of the Paris Region municipalities.

\section{Conclusion}

The nature of this paper is methodological; its objective was to check the empirical consequences of using different models for measuring Local Job Accessibility. To do so, we identified four key elements of LJA measurement (job proximity, frontier effects, job availability and local job competition) and we proposed an original model for measuring job availability where $i$ ) national data is used to control for frontier effects, $i i$ )the matching between jobs and workers is fully estimated using microdata on individual characteristics and ii) we fully take job competition into account.

By benchmarking our models with a representative sample of alternative models, we show that using different methods does indeed lead to different empirical results. More significantly, we show that (for the Paris region) some elements have stronger empirical effects than others: for example, using timeor distance-based proximity measures matter more than the specification of the decay function itself. Also, the scope of the methodologically-induced empirical variations can be different across the region's municipalities, depending from their distance to the region's administrative frontier, their unemployment levels or the presence of distant municipalities with overlapping job prospection areas. In particular, failing to fully estimate the job availability element of LJA assessment may lead to overestimate the local job accessibility of particularly under-privileged areas, which may have serious consequences when designing local unemployment-alleviating public policies.

In LJA assessment, the rule does therefore make the result. Ideally, when using LJA measures this would entail using several alternative techniques in preliminary work and checking that the final conclusions are robust to the LJA measurement technique choice. Second, it means that $i$ ) progressing in the creation of more and more complex and realistic models for assessing Local Job Accessibility 
and ii)claiming for a better availability of geo-localized data are worthwhile tasks.

Further research may profitably progress in many directions. For instance, our conclusions come from working on a specific urban context, the Paris Region. It remains to be seen if the relative importance of the four methodological issues addressed in this paper is robust to testing on other contexts. Also, we use the Spearman correlation coefficients in our benchmarking strategy; other criteria could be used (such as in, for example, Baradaran et Ramjerdi, 2001).Further, many important issues on the measurement of LJA were not addressed in the paper: extensions should for example include modeling LJA to flexible, part-time or multiple jobs and taking into account differentiated spatial and individual access to the transportation systems. Another extension would be focusing on particular subsets of the population. Here, because of data availability issues, our study was limited to adult male workers with no sub-setting to account for differences across qualifications, professions or occupational sectors. With different data sets one could focus on young, old, industrial or low qualified workers or any subset of particular interest for specific local labor market public policies. Also replicating this study on female workers or, even better, to re-combine micro-accurate household-level LJA measures would be interesting. Finally, because our model incorporates several key dimensions of LJA, it may be used to simulate the spatially differentiated effects of alternative local job market public policies on, for example, education, transportation or job implantation.

\section{References}

Allard, S.W., Danziger, S.H. (2002) Proximity and Opportunity: How Residence and Race Affect the Employment of Welfare, Housing Policy Debate, 13 (4), pp. 675-700.

Bania, N., Leete, L., Coulton, C. (2008) Job Access, Employment and Earnings: Outcomes for Welfare Leavers in a US Urban Labour Market, Urban Studies, 45 (11) pp. 2179-2202.

Baradaran, S and Ramjerdi, F. (2001) Performance of Accessibility Measures in Europe, Journal of Transportation and Statistics, 4 (2-3), pp. 31-48.

Cervero, R., Rood, T., Appleyard, B. (1999) Tracking accessibility: employment and housing opportunities in the San Francisco Bay area, Environment and Planning A, 31 (7), pp. 1259-1278.

Chauvel, L. (2006) Les Classes moyennes à la dérive. Paris, Seuil.

Cheshire, P. (1995) A new phase of urban development in Western Europe? The evidence for the 1980s, Urban Studies, 32, pp. 1045-1063.

Détang-Dessendre, C. and Gaigné, C. (2009) Unemployment duration, city size, and the tightness of the labor market, Regional Science and Urban Economics, 39, pp. 266-276.

DREIF, (2011) Les Franciliens utilisent autant les transports en commun que la voiture pour se rendre au travail, Ile de France à la page, 353.

Duguet, E., L'Horty, Y., du Parquet, L., Petit, P. and Sari, F. (2012) Les effets du lieu de résidence sur l'accès à l'emploi : un test de discrimination auprès de jeunes qualifiés, Économie et Statistique, 447, pp. 71-95.

Duguet, E., L'Horty, Y., Sari, F. (2009) Sortir du chômage en Île-de-France. Disparités territoriales, spatial mismatch et ségrégation résidentielle, Revue Économique, 60, pp. 979-1010. 
Dujardin, C., Selod, H. and Thomas I. (2008) Residential Segregation and Unemployment: The Case of Brussels, Urban Studies, 45(1), pp. 89-113.

Duriez, B., Ion, J., Pinçon, M., Pinçon-Charlot, M. (1991) Institutions statistiques et nomenclatures socioprofessionnelles, Revue française de sociologie, 32-1, p. 29-59.

Duru-Bellat, M. (2006) L'inflation scolaire. Paris, Seuil.

Fourgeot G., Gautié J. (1997) Insertion professionnelle des jeunes et processus de déclassement, Économie et Statistique (304-305), pp. 53-74.

Gaschet, F. and Gaussier, N. (2004) Urban segregation and labour markets within the Bordeaux Metropolitan Area: an investigation of the spatial friction, Cahiers du GRES, (2004-19), 28 p.

Gobillon, L. and Selod, H. (2007) Les déterminants locaux du chômage en région parisienne, Économie et Prévision, vol 4-5, n¹80-181, pp. 19-38.

Handy, S. and Niemeier, D. (1997) Measuring accessibility: an exploration of issues and alternatives, Environment and Planning A, 29, pp. 1175-1194.

Hansen, W. (1959) How Accessibility Shapes Land Use. Journal of the American Institute of Planners, 25, pp. 73-76.

Harris, B. (2001) Accessibility: concepts and application, Journal of Transportation and Statistics, 4 (2-3), pp. 15-30.

Héran, F. (1984) L'assise statistique de la sociologie, Économie et Statistique, 168, pp. 23-35.

Houston, D. (2005) Employability, Skills Mismatch and Spatial Mismatch in Metropolitan Labour Markets, in Urban Studies, 42(2), pp. 221-243.

Ihlanfeldt, K. and Sjoquist, D. (1998) The spatial mismatch hypothesis: a review of recent studies and their implications for welfare reform, Housing Policy Debate, 9, pp. 849-892.

Ilhanfeldt, K. (1993) The spatial mismatch between jobs and residential locations within urban areas. Cityscape, 1, pp. 219-244.

Jayet, H. (2000) Villes et marchés du travail, in Ville et emploi. Le territoire au cœur des nouvelles formes du travail, E. Perrin and N. Rousier (Eds.), Paris, L'Aube, pp. 53-64.

Johnson, R. (2006) Landing a job in urban space: the extent and effects of spatial mismatch, Regional Science and Urban Economics, 36, pp. 331-372.

Kain, J. (1968) Housing Segregation, Negro Employment, and Metropolitan Decentralization, Quarterly Journal of Economics, 82, p. 175-197.

Kain, J. (1992) The Spatial Mismatch Hypothesis: Three Decades Later, Housing Policy Debate, 3, pp. 371-460.

Kawabata, M. and Shen Qing (2007) Commuting Inequality between Cars and Public Transit: The Case of the San Francisco Bay Area, 1990-2000, Urban Studies, 44 (9), pp. 1759-1780.

Korsu, E. and Wenglenski, S. (2010) Job Accessibility, Residential Segregation, and Risk of Longterm Unemployment in the Paris Region, Urban Studies, 47(11), pp. 2279-2324.

Matas, A., Raymond, J.-L., and Roig, J.-L. (2009) Car ownership and access to jobs in Spain, Transportation Research Part A, 43, pp. 607-617?

Maurin, E. (2009) La peur du déclassement. Une sociologie des récessions. Paris, Seuil.

Morris, J.M., Dumble, P.L., and Wigan, M.R.(1979) Accessibility indicators for transport planning, Transport Research, 13 A, pp. 91-109.

Musterd, S., Ostendorf, W. and Vos, S. de (2003) Environmental effects and social mobility, Housing Studies, 18(6), pp. 877-892.

Nauze-Fichet, E. and Tomanisi, M. (2002) Diplôme et insertion sur le marché du travail : approches 
socioprofessionnelle et salariale du déclassement, Économie et Statistique, 354, pp. 21-48.

Ong, P. M. and Miller, D. (2005) Spatial and transportation mismatch in Los Angeles, Journal of Planning Education and Research, 25 (1), pp. 43-56.

Oswald, A.J. (1996) A conjecture on the explanation for high unemployment in the industrialized nations: Part I, mimeo, Warwick University.

Patacchini, E. and Zenou, Y. (2005) Spatial mismatch, transport mode and search decisions in England, Journal of Urban Economics, 58, pp. 62-90.

Raphael, S. (1998) The spatial mismatch hypothesis and black youth joblessness: evidence from the San Francisco Bay area, Journal of Urban Economics, 43, pp. 79-111.

Rogers, C. (1997) Job search and unemployment duration: implications for the spatial mismatch hypothesis, Journal of Urban Economics, 42, pp. 109-132.

Sanchez, T. W., Shen, Q. and Peng, Z. R. (2004) Transit mobility, jobs access, and low-income labour participation in US metropolitan areas, Urban Studies, 41, pp. 1313-1331.

Tovar, E. and Bourdeau-Lepage, L. (2013) Well-being Disparities Within the Paris Region. A Capabilist Spatialized Outlook. Urban Studies, forthcoming.

Klaauw, B. van der and Ours, J. van (2003) From welfare to work: does the neighborhood matter?, Journal of Public Economics, 87, pp. 957-985.

Wee, B. van, Hagoort, M. and Annema J.A. (2001) Accessibility measures with competition, Journal of Transport Geography, 9, pp. 199-208.

Weibull, J.W. (1976) An axiomatic approach go the measurement of accessibility, Regional Science and Urban Economics, 6, pp. 357-379. 
Appendix1

Table 2 here

Appendix 2

Table 3 here 


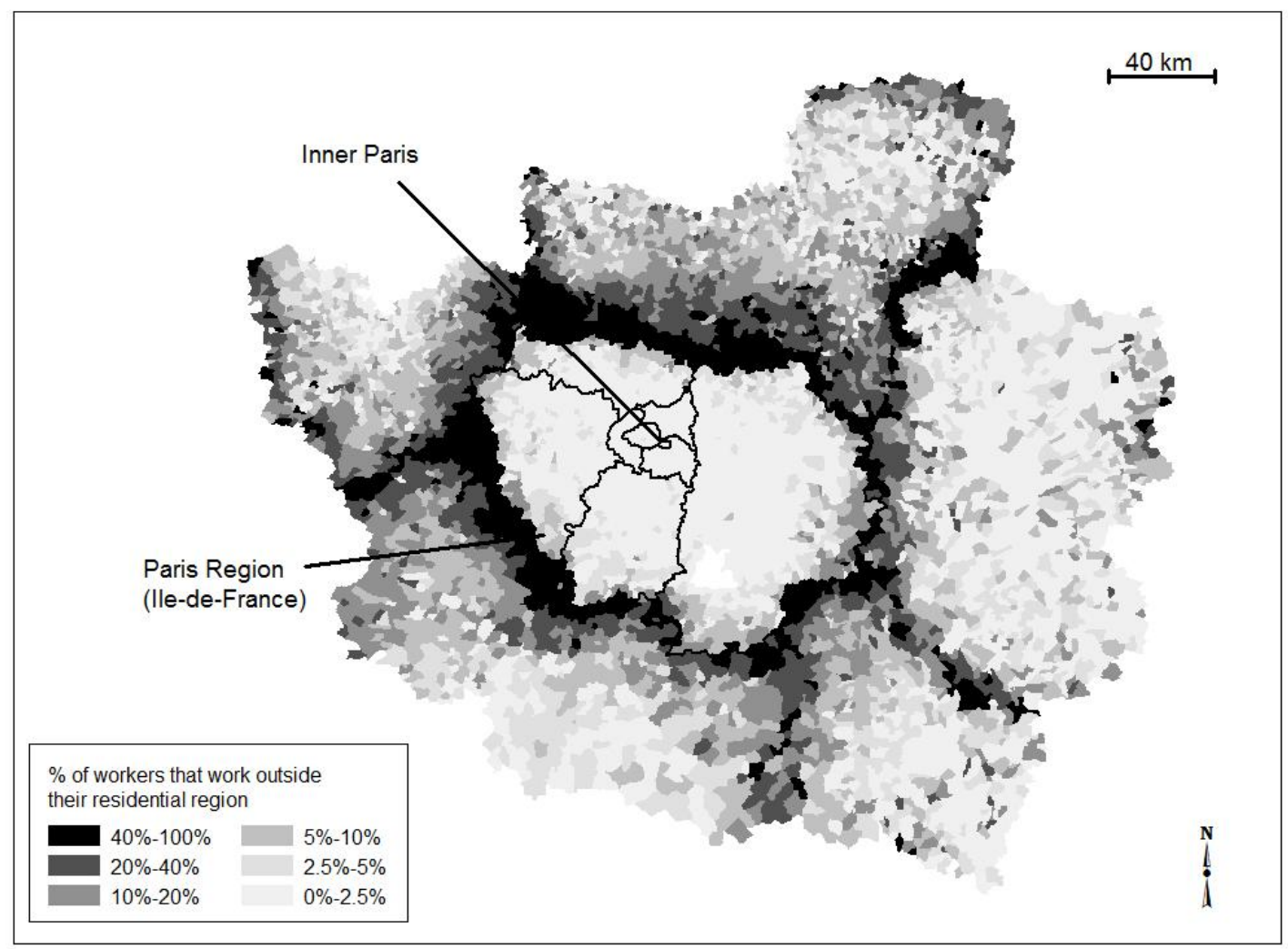

Figure 1. Frontier effects in the Paris Region

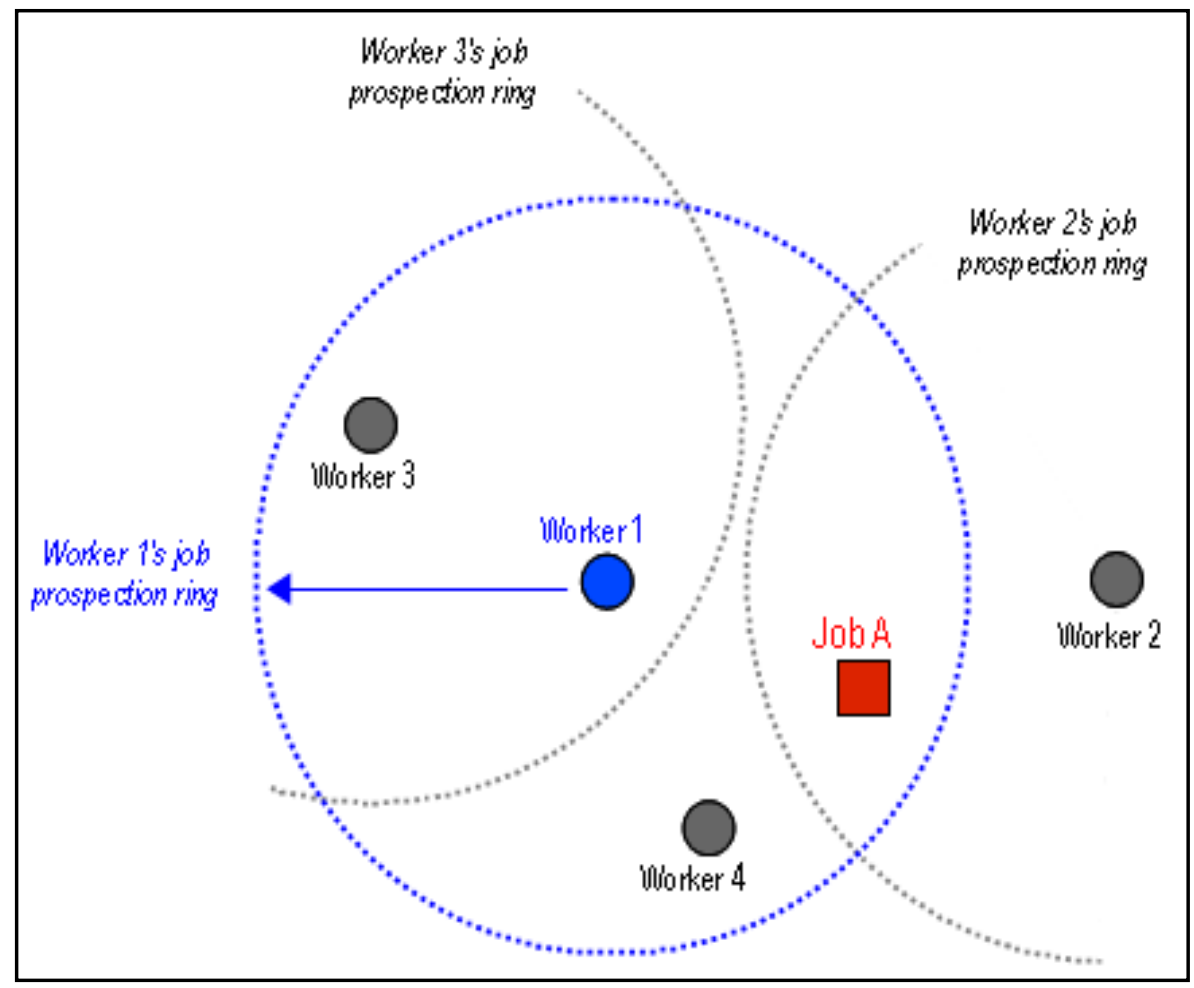

Figure 2. Partial vs. Full Job Competition 


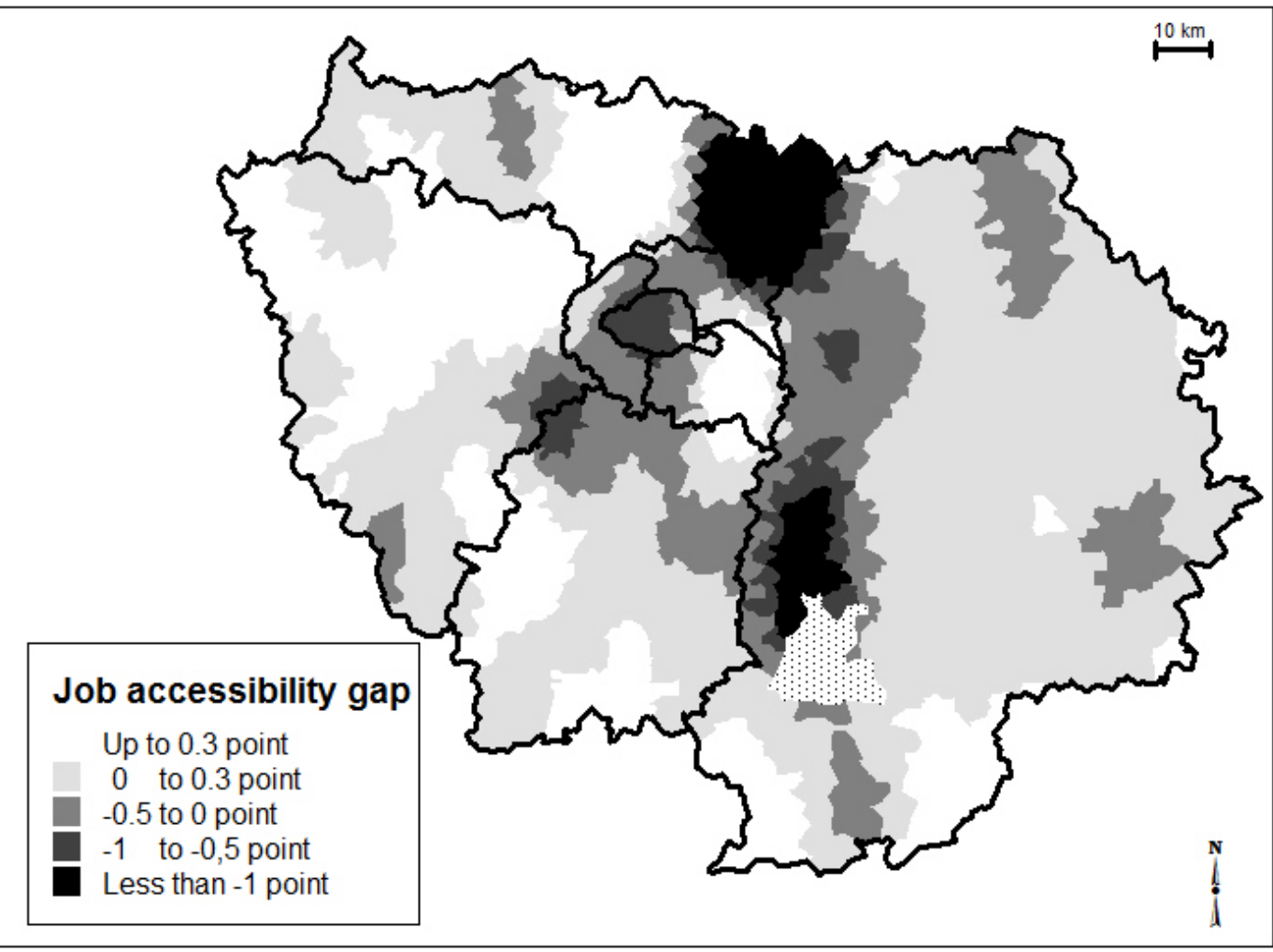

Figure 3. Job accessibility difference between models with and without a full estimation of the job availability probability 


\begin{tabular}{|c|c|c|c|c|c|c|}
\hline \multirow[b]{2}{*}{ Model } & \multicolumn{6}{|c|}{ Municipalities (number) } \\
\hline & $\begin{array}{c}\text { All } \\
(1300)\end{array}$ & $\begin{array}{l}\text { Large* }^{*} \\
(299)\end{array}$ & $\begin{array}{c}\text { Frontier }^{\#} \\
(497)\end{array}$ & $\begin{array}{c}\text { Deprived }^{\$} \\
\text { (145) }\end{array}$ & $\begin{array}{c}\text { Unemployed }^{8} \\
(322)\end{array}$ & $\begin{array}{c}\text { Residential }^{\%} \\
(221)\end{array}$ \\
\hline $\mathbf{N}$ & 0.856 & 0.811 & 0.587 & 0.621 & 0.455 & 0.594 \\
\hline T1 & 0.897 & 0.701 & 0.478 & 0.977 & 0.978 & 0.961 \\
\hline $\mathbf{T 2}$ & 0.931 & 0.724 & 0.584 & 0.994 & 0.994 & 0.990 \\
\hline T3 & 0.948 & 0.764 & 0.667 & 0.998 & 0.998 & 0.996 \\
\hline G1 & 0.447 & 0.239 & 0.003 & 0.626 & 0.538 & 0.448 \\
\hline G2 & 0.453 & 0.241 & -0.010 & 0.647 & 0.555 & 0.470 \\
\hline G3 & 0.463 & 0.261 & 0.046 & 0.655 & 0.561 & 0.479 \\
\hline $\mathbf{F}$ & 0.887 & 0.689 & 0.533 & 0.924 & 0.880 & 0.907 \\
\hline C & 0.765 & 0.623 & 0.448 & 0.826 & 0.823 & 0.673 \\
\hline $\mathbf{A}$ & 0.971 & 0.881 & 0.806 & 0.996 & 0.998 & 0.997 \\
\hline \multicolumn{7}{|c|}{$\begin{array}{l}\text { All Pearson correlation coefficients are significant at } 1 \% \text {. } \\
\text { * Municipalities with over } 4,500 \text { inhabitants. This subsample includes more than } 85 \% \text { of the Paris region population. } \\
\text { \# Frontier municipalities and their neighbors (assessed using a level } 2 \text { Queen binary contiguity matrix). }\end{array}$} \\
\hline \multicolumn{7}{|c|}{$\begin{array}{l}\text { \$ Particularly disadvantaged municipalities that are the target of specific local public policies and house one or more } \\
\text { Priority zone for Education (Zone d'éducation prioritaire, ZEP) or Difficult Urban Zone (Zone urbaine sensible, ZUS). } \\
\text { \$ Municipalities where men-unemployment was over } 6.5 \% \text { in } 2006 \text {. } \\
\text { \% Urban municipalities that belong to the Paris urban zone (as defined by the National Institute for Statistics, INSEE) but } \\
\text { where there are more inhabitants that jobs. These residential municipalities (banlieues dortoir) are located at the outskirt } \\
\text { of the Paris urban zone. }\end{array}$} \\
\hline
\end{tabular}




\section{Appendix1. Gap between estimated and observed unemployment by district}

\begin{tabular}{llc}
\hline & Actual & Estimated \\
\hline Estimated(1) & & \\
Total & $8.5 \%$ & $7.4 \%$ \\
Paris & $9.3 \%$ & $10.8 \%$ \\
Seine et Marne & $7.0 \%$ & $5.3 \%$ \\
Yvelines & $6.5 \%$ & $5.4 \%$ \\
Essonne & $6.4 \%$ & $5.5 \%$ \\
Hauts-de-Seine & $7.8 \%$ & $8.1 \%$ \\
Seine-St-Denis & $11.7 \%$ & $10.7 \%$ \\
Val-de-Marne & $8.1 \%$ & $8.0 \%$ \\
Val-d'Oise & $8.7 \%$ & $6.6 \%$ \\
\hline
\end{tabular}

(1) Estimation obtained by using our estimation applied to Census Dwellings sample.

(2) Pôle-Emploi for the unemployment rate and Dads for the qualification in the private sector (males between 20 and 55 years old). 


\section{Appendix2. Descriptive Statistics}

\begin{tabular}{|c|c|c|}
\hline & French LFS & French Census \\
\hline \multicolumn{3}{|l|}{ Individual variables } \\
\hline 15-19 years & $0,3 \%$ & $0,4 \%$ \\
\hline 20-24 years & $4,9 \%$ & $5,6 \%$ \\
\hline 25-39 years & $46,4 \%$ & $46,4 \%$ \\
\hline $40-54$ years & $48,4 \%$ & $47,6 \%$ \\
\hline Age & 38,711 & \\
\hline Married & $45,4 \%$ & $54,0 \%$ \\
\hline Children less than 6 years old & $14,8 \%$ & $29,2 \%$ \\
\hline Children between 6 and 18 years old & $23,9 \%$ & $35,9 \%$ \\
\hline \multicolumn{3}{|l|}{ Diploma variables } \\
\hline Upper education & $12,2 \%$ & $15,9 \%$ \\
\hline Graduate & $11,8 \%$ & $13,1 \%$ \\
\hline BAC pro & $9,6 \%$ & $9,5 \%$ \\
\hline $\mathrm{BAC}$ & $5,8 \%$ & $7,1 \%$ \\
\hline $\mathrm{BEP}$ & $31,3 \%$ & $32,6 \%$ \\
\hline No degree & $29,3 \%$ & $21,8 \%$ \\
\hline \multicolumn{3}{|l|}{ Oswald's Hypothesis } \\
\hline House & $47,2 \%$ & $55,5 \%$ \\
\hline Size of the House & $27,4 \%$ & $17,5 \%$ \\
\hline Owner-occupied & $45,5 \%$ & $51,4 \%$ \\
\hline Living in publicly owned units & $18,8 \%$ & $15,6 \%$ \\
\hline Renter-occupied in a no publicly owned units & $35,7 \%$ & $33,0 \%$ \\
\hline \multicolumn{3}{|l|}{ Neighbourhood variable } \\
\hline Unemployment rate & $7,8 \%$ & $7,7 \%$ \\
\hline \multicolumn{3}{|l|}{ Localisation } \\
\hline Ile-de-France & $21,7 \%$ & $20,4 \%$ \\
\hline Acquitaine & $3,8 \%$ & $4,7 \%$ \\
\hline Bretagne & $3,9 \%$ & $5,0 \%$ \\
\hline Centre & $2,9 \%$ & $4,2 \%$ \\
\hline Lorraine & $4,0 \%$ & $4,0 \%$ \\
\hline Nord-pas-Calais & $9,2 \%$ & $6,7 \%$ \\
\hline Paca & $5,6 \%$ & $6,9 \%$ \\
\hline Rhône-Alpes & $10,0 \%$ & $10,0 \%$ \\
\hline Other & $38,9 \%$ & $38,2 \%$ \\
\hline \multicolumn{3}{|l|}{ Labor status in $t$} \\
\hline Unemployed & $13,0 \%$ & $8,6 \%$ \\
\hline Employed & $87,0 \%$ & $91,4 \%$ \\
\hline \multicolumn{3}{|l|}{ Labor status in $t+1$} \\
\hline Out of the labor market & $3,8 \%$ & n.a \\
\hline Unemployed & $10,4 \%$ & n.a \\
\hline
\end{tabular}

Source: French LFS and Census (Dwellings database). 